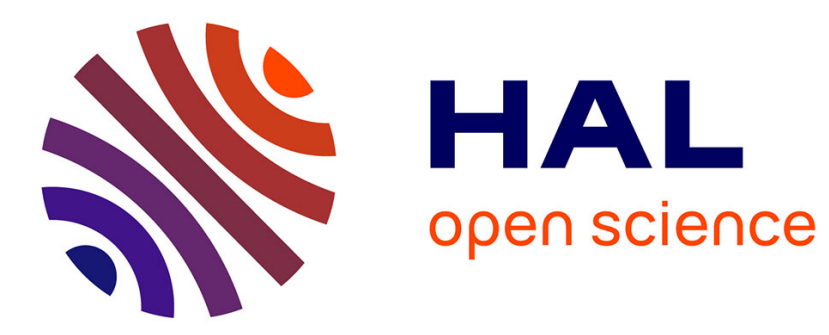

\title{
A multiscale in situ high temperature high resolution transmission electron microscopy study of ThO2 sintering
}

Renaud Podor, V. Trillaud, G. Nkou Bouala, Nicolas Dacheux, C. Ricolleau, Nicolas Clavier

\section{To cite this version:}

Renaud Podor, V. Trillaud, G. Nkou Bouala, Nicolas Dacheux, C. Ricolleau, et al.. A multiscale in situ high temperature high resolution transmission electron microscopy study of $\mathrm{ThO} 2$ sintering. Nanoscale, 2021, 13 (15), pp.7362-7374. 10.1039/D1NR00956G . hal-03337033

\section{HAL Id: hal-03337033 \\ https://hal.science/hal-03337033}

Submitted on 18 Oct 2021

HAL is a multi-disciplinary open access archive for the deposit and dissemination of scientific research documents, whether they are published or not. The documents may come from teaching and research institutions in France or abroad, or from public or private research centers.
L'archive ouverte pluridisciplinaire HAL, est destinée au dépôt et à la diffusion de documents scientifiques de niveau recherche, publiés ou non, émanant des établissements d'enseignement et de recherche français ou étrangers, des laboratoires publics ou privés. 
A multiscale in situ High Temperature High Resolution Transmission Electron Microscopy study of $\mathrm{ThO}_{2}$ sintering

R. Podor ${ }^{1, *}$, V. Trillaud ${ }^{1}$, G.I. Nkou Bouala ${ }^{1,2}$, N. Dacheux ${ }^{1}$, C. Ricolleau ${ }^{3}$ and N. Clavier ${ }^{1}$

${ }^{1}$ ICSM, Univ Montpellier, CNRS, CEA, ENSCM, Bagnols-sur-Cèze, France

${ }^{2}$ LaBoMap, Arts \& Métiers ParisTech, rue Porte de Paris F-71250 Cluny, France

${ }^{3}$ Laboratoire de Matériaux et Phénomènes Quantiques, CNRS UMR 7162, Université de Paris, 75013 Paris

* Corresponding author

\section{Graphical abstract}

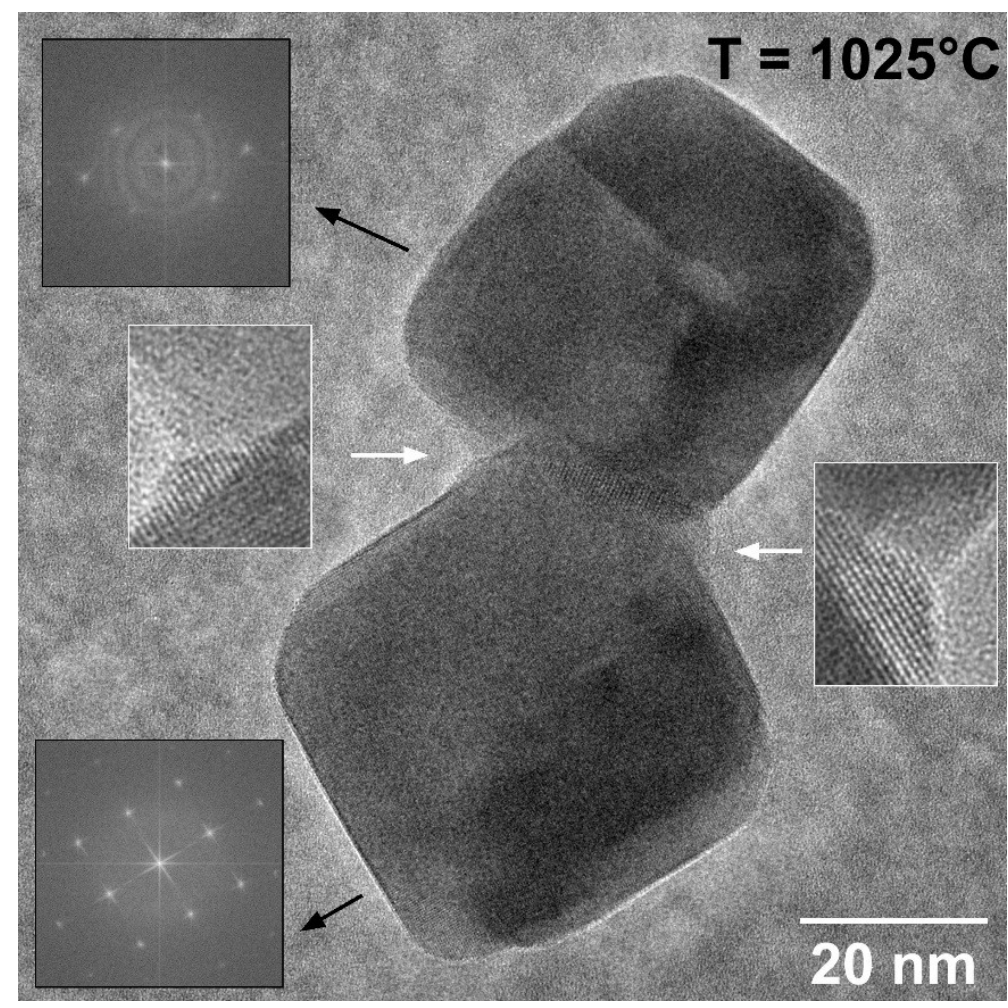

Keywords: High temperature, HRTEM, sintering, neck formation, in situ, $\mathrm{ThO}_{2}$ 


\section{Abstract}

Two-grain model systems formed by $\mathrm{ThO}_{2}$ nanospheres have been used to experimentally study for the first time the initial stage of sintering from room temperature to $1050^{\circ} \mathrm{C}$ using High Temperature High Resolution Transmission Electron Microscopy. In each grain, oriented attachment drove the reorganization and growth of the crystallites up to $300^{\circ} \mathrm{C}$ to form a pseudo single crystal. Crystallite size kept growing up to $950^{\circ} \mathrm{C}$. At this temperature, a fast transformation probably corresponding to the elimination of stacking faults or dislocation walls led to the formation of single-crystals. The contact formed at room temperature between the two grains was stabilized during heat treatment by a slight reorientation of the crystallographic planes $\left(T \approx 400^{\circ} \mathrm{C}\right)$, leading the neck to be formed by numerous boundaries between the crystallites. At higher temperatures, the neck evolved and stabilized in the form of a plane of crystallographic orientation mismatch between the grains, which corresponds to the usual definition of the grain boundary. The growth of the neck by the addition of atomic columns was further observed in real time and quantified. At $\mathrm{T}=950^{\circ} \mathrm{C}$, the evolution of the macroscopic sintering parameter $\lambda$ was obtained from HT-HRTEM images and indicated that the neck formation mostly processed through volume diffusion. 


\section{Introduction}

Sintering is a process of materials elaboration by heating a shaped powder (sometimes under pressure) without reaching complete melting. Although modern approaches and recent advances in imaging techniques such as X-ray microtomography showed that the three-dimensional evolution of the microstructure of a powder compact is a deeply complex mechanism ${ }^{1-3}$, solid-state sintering is still frequently simplified as a three-step process starting from the formation and growth of necks between the grains. This initial stage is generally described through mathematical models based on geometrical and crystallographic simplifications, leading to consider two spherical and monocrystalline grains in contact, while real-life grains are mostly polycrystalline (i.e. formed by several elementary crystallites) and often present random shapes. The quantities of matter exchanged between the two grains were then computed using different methods including molecular dynamics ${ }^{4}$, Monte Carlo ${ }^{5}$, or Discrete Elements Methods ${ }^{6}$.

Conversely, only few experimental data showing this matter exchange are reported in the literature. They are mainly based on electron microscopy techniques that allow the direct observation of the morphological modifications associated to the heat treatment of powdered materials ${ }^{7-11}$. These works have experimentally evidenced nanometric / atomic scale processes that can drive the first stage of sintering. Most of the materials that have been studied are metallic ${ }^{12,13}$ or $\mathrm{CeO}_{2}$ nanoparticles ${ }^{14-17}$. The sintering behavior of large monocrystalline grains (several tens of nanometers) ${ }^{18}$, large polycrystalline aggregates ${ }^{19,20}$ or groups of grains ${ }^{21,22}$ has also been monitored by in situ High Temperature Transmission Electron Microscopy but remains limited to a few studies. Moreover, the authors generally pay attention to the general behavior of the grains / aggregates at high temperature, but only few information relative to atomic scale mechanisms occurring at high temperature are reported $^{18}$.

When dealing with the solid-state sintering of polycrystalline materials, where grains can be viewed as aggregates constituted by nanoscale crystallites, oriented attachment (OA), first observed 
by Penn and Banfield (1998) ${ }^{23}$, is now considered as one of the main mechanisms responsible for the growth of the crystallites ${ }^{8,24,25}$. It is driven by the minimization of the surface energy through alignment of the crystallites along identical crystallographic orientations ${ }^{26,27}$. Some works have also reported the rotation of one grain relative to the others during the first stage of sintering even for micrometric metal particles $18,28,29$.

Although clearly evidenced by experimental data, these mechanisms are not yet considered in the mathematical models developed to describe the first stage of sintering. Nkou Bouala et al. ${ }^{11}$ have shown that there was a good agreement between modelling and experiments when considering a system composed by two monocrystalline grains of $\mathrm{CeO}_{2}$. However, sintering was accelerated if the two grains were initially polycrystalline. Same authors then concluded that in real solids, the first stage of sintering was controlled not only by the behavior of the grains themselves, but also by crystallite rearrangements within the grains. Although they provide reliable qualitative descriptions, the classical two-grain models established in the 1960 's ${ }^{30}$ and developed since then ${ }^{4,31}$ mostly fail to describe correctly the evolution of sintering rate for real materials, even when considering simple geometries.

Numerical models can be improved by taking into account new insights coming from microscopic observations and new models including polycrystalline grains are currently under development ${ }^{31}$. However, many questions remain pending such as what happens at the very beginning of the first stage when the grains are in contact or what can be the role of polycrystallinity in the grains? It is also important to understand how the crystallites forming the grains rearrange themselves when heating the sample and how the grains rearrange one relative to each other. These missing pieces are essential to clearly understand which are the parameters controlling the formation of necks between the grains during the first stage of solid-state sintering.

In the present study, we propose to bring new insights into the very early stages of sintering of oxide materials through High Temperature - High Resolution TEM observations (HT-HRTEM) with a sub-second temporal resolution. $\mathrm{ThO}_{2}$ have been chosen as a model material, owing to its remarkable 
applications in the energy industry (nuclear fuel ${ }^{32}$, oxygen sensor ${ }^{33} \ldots$ ), and the fact that its fluorite structure is adopted by many metal dioxides $\left(\mathrm{YSZ}, \mathrm{CeO}_{2}, \mathrm{UO}_{2}, \mathrm{PuO}_{2} \ldots\right)$. Also, as $\mathrm{Th}(\mathrm{IV})$ is the unique stable oxidation state of thorium on the temperature and pressure range investigated, thorium oxide possesses a strict $\mathrm{ThO}_{2}$ stoichiometry that makes it insensitive to $\mathrm{PO}_{2}$, and avoids any bias due to the atmosphere surrounding the sample during the observations. Last, the first stage of sintering of 250 $\mathrm{nm}$ diameter $\mathrm{ThO}_{2}$ has been already studied experimentally by Nkou Bouala et al. ${ }^{34}$ by High Temperature - Environmental Scanning Electron Microscopy (HT-ESEM) which provides a microscopic point of comparison. The present work will be focused on the use of polycrystalline $\mathrm{ThO}_{2}$ nanospheres of $50 \mathrm{~nm}$ in diameter, which are transparent to the $200 \mathrm{kV}$ electron beam. This size was chosen to be between that of nanoparticles $(3-10 \mathrm{~nm})$, which are generally monocrystalline and for which sintering behavior can be described by models, and real grains (from 0.5 to a few hundreds of micrometers), which are generally polycrystalline. We focused our attention on an experimental system constituted by two $\mathrm{ThO}_{2}$ nanospheres, regarding particularly i) the evolution of the neck between the grains at the grain scale and ii) the growth of the crystallites within the grains at the nanometer and atomic scale. Particularly, the modification of the arrangement of the crystallites, their relative orientations, the neck size... will be monitored as a function of temperature.

\section{Materials and methods}

\section{Preparation of $\mathrm{ThO}_{2}$ nanospheres}

The synthesis of $\mathrm{ThO}_{2}$ nanospheres was performed through an hydrothermal route inspired from the protocol initially reported by Wang et al. ${ }^{35}$ In this aim, $2 \times 10^{-4}$ mole of thorium nitrate pentahydrate (supplied by Sigma-Aldrich) was first dissolved in $5 \mathrm{~mL}$ of deionized water, along with $10^{-4}$ mole of urea and $2.7 \times 10^{-3}$ mole of glycerol, here used as complexing and shaping agents, respectively. The starting mixture was aged for 10 minutes under magnetic stirring then transferred to a $23 \mathrm{~mL}$ autoclave (Parr). It was finally heated under hydrothermal conditions at $120^{\circ} \mathrm{C}$ for 10 hours. 
The white precipitate collected by centrifugation at $4500 \mathrm{rpm}$ was further washed twice with deionized water and ethanol, and then dried overnight at $60^{\circ} \mathrm{C}$. X-ray diffraction characterization was already reported in our previous work ${ }^{34}$. It confirmed the formation $\mathrm{ThO}_{2}$ crystallizing in the cubic $\mathrm{Fm}-3 \mathrm{~m}$ space group (fluorite-type structure), while Rietveld refinement of the XRD pattern allowed us to estimate the average crystallite size to be under $5 \mathrm{~nm}$. Furthermore, image analysis of ESEM and TEM micrographs revealed that a monodisperse powder was obtained. It was composed by isolated nanospheres with an average diameter of $57 \pm 9 \mathrm{~nm}$ (see Supplementary File S1). From these results, the nanospheres can be viewed as aggregates made of several elementary crystallites. For simplification purposes, these aggregates will be denominated as grains in the rest of the paper.

Also, it is important to underline that the absence of two-grain systems already formed during the synthesis process was thoroughly checked. In this aim, TEM observations led us to conclude that all the grains were separated, meaning that no neck between the grains formed in solution was present at the beginning of our experiments.

\section{High Temperature - High Resolution Transmission Electron Microscopy}

A Jeol ARM microscope operating at $200 \mathrm{kV}$ and equipped with a spherical aberration corrector was used to perform the experiments. A Protochips Inc. Atmosphere heating specimen holder ${ }^{36-38}$ was attached to the microscope, allowing us to reach a maximum temperature of $1100^{\circ} \mathrm{C}$ through the circulation of a gas flow around the sample. The sample and the gas are isolated from the high vacuum TEM chamber by two $50 \mathrm{~nm}$ thick $\mathrm{Si}_{\mathrm{x}} \mathrm{N}_{\mathrm{y}}$ windows. the detailed heating procedure has been described by Chmielewski et al. ${ }^{39}$. Prior to the observations, about $5 \mathrm{mg}$ of $\mathrm{ThO}_{2}$ powder were mixed with $2 \mathrm{~mL}$ of acetone and dispersed by ultrasonication. Then, a $1 \mu \mathrm{L}$ drop was deposited on the $\mathrm{Si}_{x} \mathrm{~N}_{\mathrm{y}}$ window of the sample holder. The second window was broken in order to perform the experiment under high vacuum conditions in the microscope chamber with the aim to ensure a better image resolution. The sample was heated under vacuum with a $30^{\circ} \mathrm{C} / \mathrm{min}$ heating rate from room temperature (RT) up to a 
maximum temperature of $1050^{\circ} \mathrm{C}$. The microscope was associated with a OneView Gatan ${ }^{\mathrm{TM}}$ camera: $^{2}$ the recording frequency was fixed to 7 images per second with a $2048 \times 2048$ pixels resolution $(16$ bits grey levels) during the heat treatment. The total duration for one experiment ranged from one to two hours.

During the experiments, the heating ramp was stopped several times and different isothermal plateaus were managed. When the temperature was stabilized, the blurring effect due to the heat treatment was avoided and images were recorded at several magnifications in order to observe sintering at different scales. Several systems composed of two nanospheres were observed to ensure the representativeness of the dataset.

Image analyses

During one typical experiment, approximately 22000 images were recorded. All the blurred images - mainly caused by sample and/or sample holder deformation during heating - were first eliminated. This corresponds to approximatively $50 \%$ of the total number of images. Then, the stacks of images were aligned using Fiji ${ }^{40} /$ Linear Stack Alignment with SIFT plugin ${ }^{41}$. Due to the highresolution mode used during image recording, the images were used in the direct space for the determination of interatomic distances. Then, Fast Fourier Transform (FFT) patterns of images from selected zones were computed to follow the evolution of the crystal structure and the corresponding inter-reticular distances.

A specific image analysis strategy was developed to characterize the crystallographic transformations occurring during the heat treatment using series of FFT patterns. A particular diffraction spot (arbitrarily set to the (200) planes) was first selected to monitor the variations of its shape and position as a function of temperature. In this aim, a polar projection of the FFT pattern series was achieved using polar_transformer plugin for image ${ }^{42}$. In this representation, one line corresponds 
to a family of planes with the same orientation (i.e. (200)) at a given temperature. The variation of the positions was observed along the stack of images, i.e. as a function of temperature. This representation was used to describe the crystallographic transformations occurring within a grain during the first step of sintering.

\section{Results}

\section{Observations of the as-deposited grains}

Prior to any heat treatment, the as-deposited nanospheres (grains) were carefully characterized. If Rietveld refinement of XRD patterns already shown that they were constituted by several crystallites, HRTEM observations revealed that these latter were not completely independent one from the other. Indeed, the FFT patterns (Figure 1a) determined from the images of each grain indicated that the crystallites were slightly misoriented with regards to a given orientation inside the grain. Each grain then can be described as a mosaic, formed by a large number of nanometric single crystals, randomly misoriented around the main lattice direction. This misorientation modifies the electron diffraction spots in the SEAD pattern (or in the pseudo spots of a FFT pattern) which becomes broadened, as misorientation induces a defocusing effect in the reflection plane. The misorientation angle was determined, as a first approach, as the half width at half maximum of the diffraction spot. In the present case, it was approximately $5^{\circ}$ around the [200] and [220] directions at room temperature. This nearly perfect alignment of the crystallites in the grain was probably the consequence of a selfassembly process occurring during the synthesis. Indeed, such mechanism was frequently observed during the hydrothermal treatment of organics mixtures and tetravalent actinides in acidic solutions, leading nanometric $\mathrm{An}(\mathrm{IV})$ oxide/hydroxide crystallites to form spherical particles ${ }^{43-46}$. From HRTEM images, the average size of the crystallites in each grain was approximately equal to 1-3 nm (Figure 1b), in good agreement with the XRD data. High magnification images revealed that in the zone of contact, the crystallites were not organized and pores were observable. Thus, the neck between the 
grains was not formed before the heat treatment. However, as the grains were not perfectly spherical, the contact still cannot be described as a perfect single-point (Figure 1b).

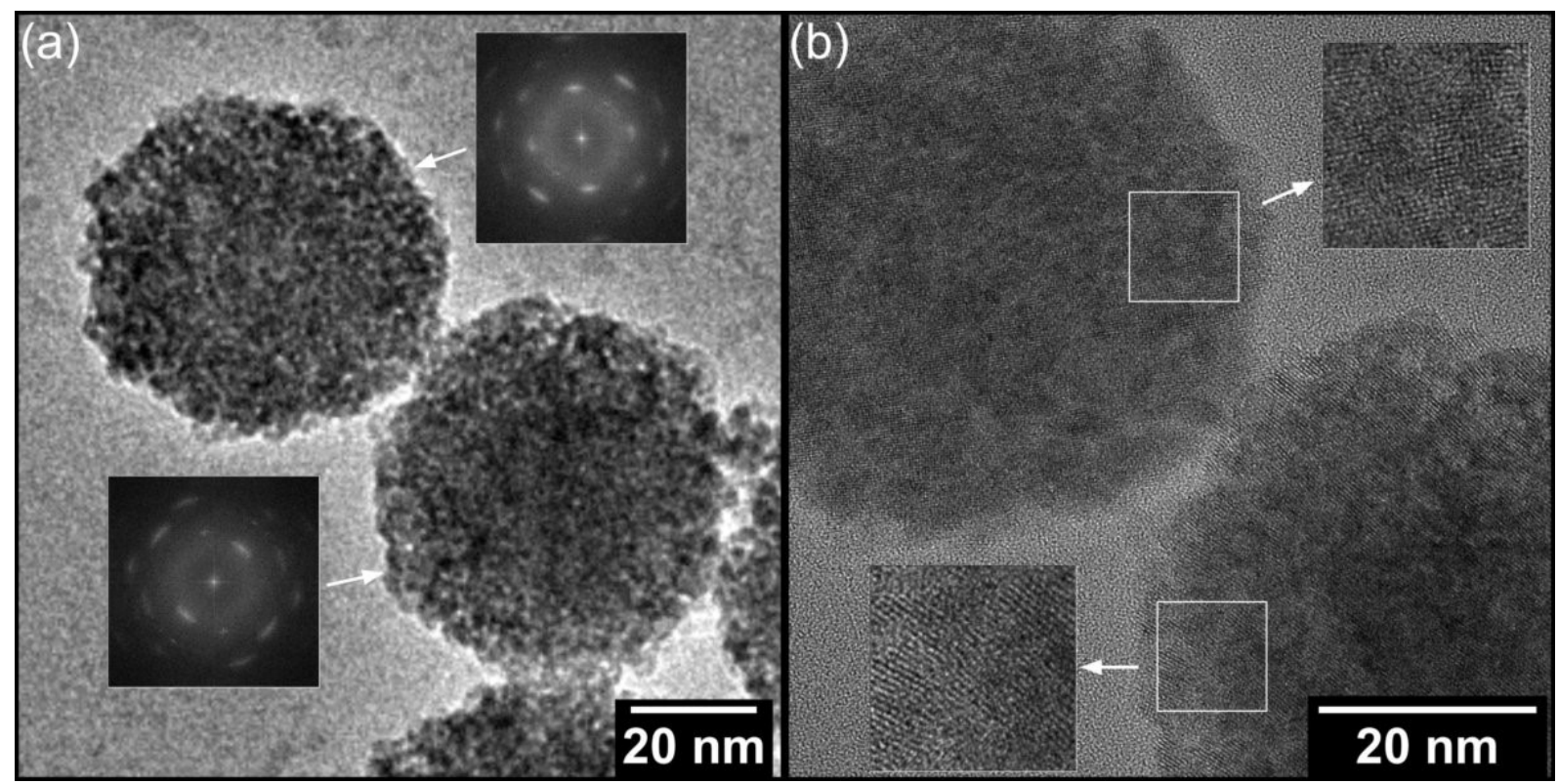

Figure 1. a) General view of an as-prepared two-grain system (50 nm in diameter) with FFT patterns corresponding to each grain obtained from the HRTEM image. b) High resolution image of the point-contact region between the two grains. White squares correspond to the zones presented in inserts for high magnification observations (10 $\times 10 \mathrm{~nm}^{2}$ in each grain).

\section{Description of the systems obtained after heat treatment}

Different two-grain systems were observed after heating, leading to two possible scenarios. First, the contact-point between the grains did not necessarily develop to form a neck. In this case, the grains were finally isolated after heating (Supplementary File S2). This clearly indicated that no neck was formed during the synthesis of nanospheres, i.e. prior to heat treatment. In this case, the sintering of crystallites within a single grain was faster than the formation of the neck between the grains. The average grain size decreased by about $5 \%$ in diameter and the contact between the grains was lost during the heat treatment. The competition between inner grains sintering and neck formation has already been discussed by Nkou Bouala et al. ${ }^{11}$. The authors showed that the crystallite growth within aggregates and the eventual elimination of residual porosity processed through oriented attachment then solid state diffusion, and generally occurred before the sintering of aggregates characterized by 
the formation of necks. Previous work already evidenced the existence of inner pores within the nanospheres ${ }^{34}$.

The general features observed when a neck was formed between the grains are illustrated in Figure 2a for a system heated during 15 minutes at $1025^{\circ} \mathrm{C}$ (see Supplementary File S3 for the complete movie). The grains exhibited a cubic shape typical of the materials crystallizing in the fluorite-type structure, and no pore was evidenced. The FFT pattern obtained from the whole image clearly showed that each grain was monocrystalline, but that the two grains did not share the same orientation (Figure 2b). This was also observable on the high magnification images of the neck (Figure 2a). The crystallographic networks of both grains are shown in the high resolution TEM images (inserts in Figure 2a). As the crystallographic orientation of the two grains differs, a planar grain boundary is formed in the neck zone. This disorientation led to the grain boundary to be a low-energy interface, as evidenced by its peculiar physico-chemical properties, such as chemical durability ${ }^{47}$. The FFT patterns obtained for the two grains are reported on Figure $2 \mathrm{~b}$ where the red and green spots correspond respectively to the upper and lower grains. The same planes families ((200) and (220)) are identified on both crystals, with a $21^{\circ}$ misorientation angle between both grains.

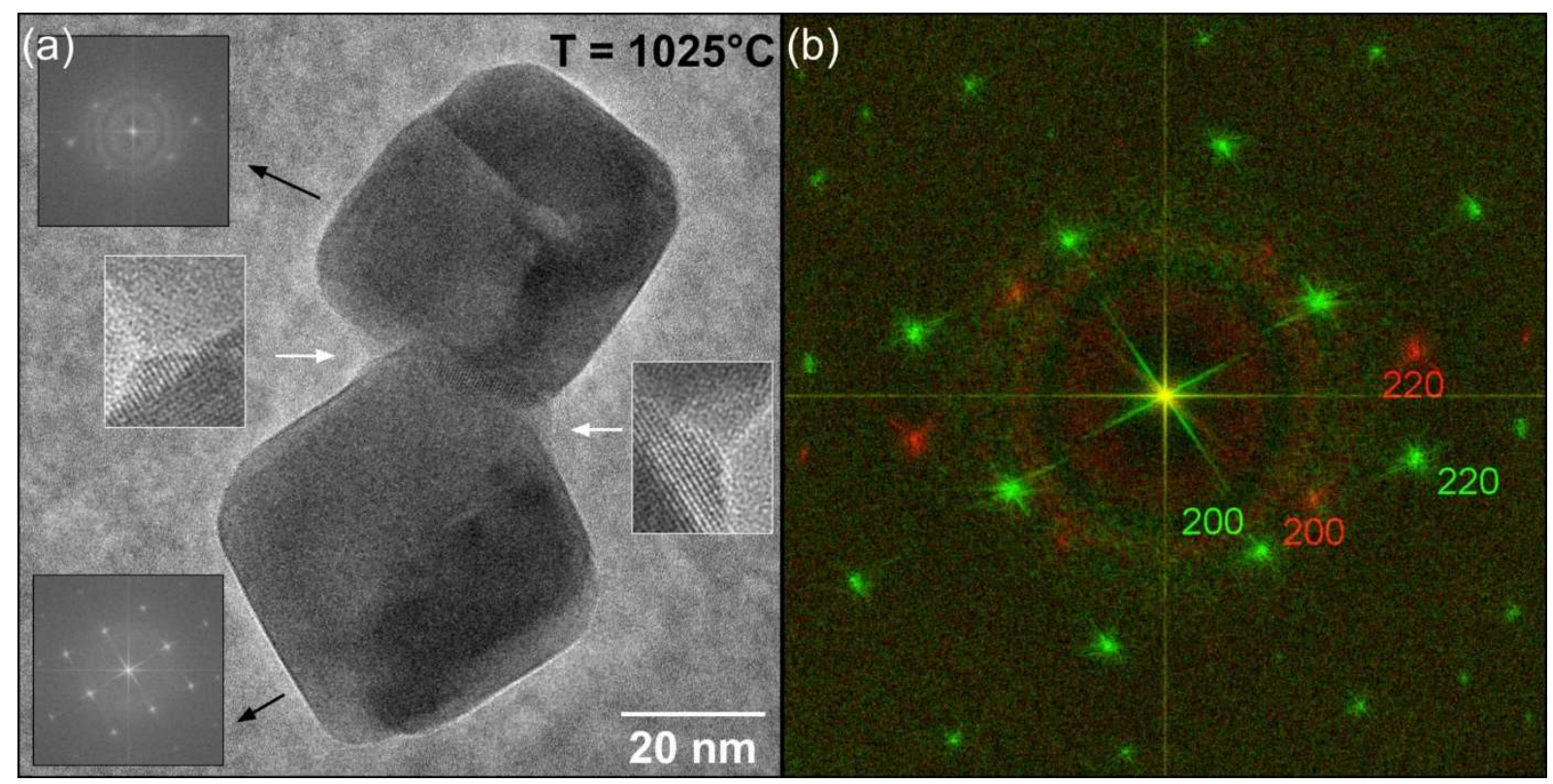


Figure 2. General observations by HRTEM of a two-grain system after heating at $1025^{\circ} \mathrm{C}$ in the TEM. a) Two-grain system of $50 \mathrm{~nm}$ in diameter with FFT patterns corresponding to each grain (size of the high magnification inserts is $5 \times 6 \mathrm{~nm}^{2}$ ). b) Combined and indexed FFT patterns of both grains. Red = diffraction spots of the upper grain; Green = diffraction spots of the lower grain

\section{Electron beam effect}

The effect of the electron beam irradiation is an important parameter that could affect the validity of the measurements. Then, it is of primary importance to check if it modifies locally the sample during the observation. In this aim, the morphology of several nanospheres was only observed during isothermal plateaus (7 images were recorded during the heat treatment) and no significant morphological differences were evidenced when comparing to grains observed continuously (Figure 3a). Thus, the effect of the electron beam remained limited during the heating ramp up to $950^{\circ} \mathrm{C}$.

At $950^{\circ} \mathrm{C}$, the morphology of the sample changed under the electron beam and the formation of a single crystal was observed. Conversely, neighbor grains did not undergo any transformation. Nevertheless, as soon as these grains were illuminated by the electron beam, the transformation begun. When the two-grain system was observed at $\mathrm{T}=1025^{\circ} \mathrm{C}$ after heating in the TEM, the monocrystalline aspect of the grains was obtained out of the electron beam illumination field (Figure 2 ), which indicated that the sample evolved naturally towards this morphology at this temperature. Thus, the electron beam can provide a supplementary amount of energy that can increase the temperatures within the nanoparticles (probably up to a few ten of ${ }^{\circ} \mathrm{C}$ ). This additional heating then triggered mass transport leading to sintering phenomena and the evolution of the grains towards a single crystal.

Complete description of the first stage of sintering

Using $50 \mathrm{~nm}$ diameter $\mathrm{ThO}_{2}$ nanospheres, the first stage of sintering was continuously observed on a two isolated grains system from room temperature up to $950^{\circ} \mathrm{C}$. The complete description of the different processes observed can be reported, from the grain scale to the atomic scale. 


\section{Observations at the grain scale}

In the present study, HT-HRTEM images were recorded regularly from room temperature to $950^{\circ} \mathrm{C}$, in order to describe the general behavior of a two-grain system (Figure 3). Between each temperature isotherm, the sample was heated with a $15^{\circ} \mathrm{C} / \mathrm{min}$ heating rate. The experiment was stopped when the $\mathrm{SiN}_{1-\mathrm{x}}$ membrane began to recrystallize, at about $950^{\circ} \mathrm{C}$ under high vacuum.

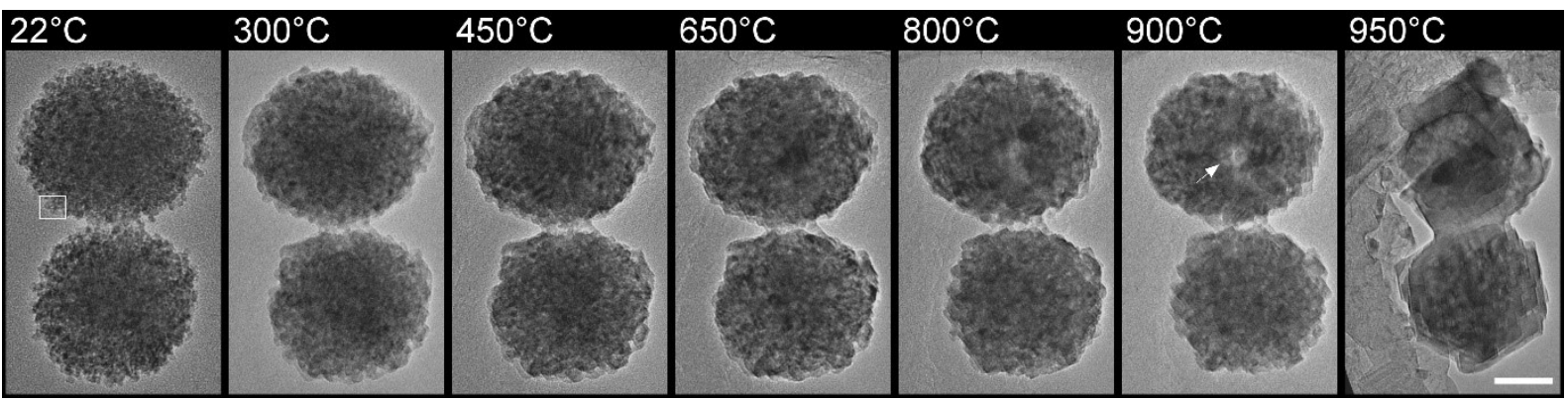

Figure 3. HT-TEM images recorded at different temperatures during in situ heating of a two $\mathrm{ThO}_{2}$ grains system $(50 \mathrm{~nm}$ in diameter) at low magnification (scale bar $=20 \mathrm{~nm}$ ). The white arrow reported on the image recorded at $T=900^{\circ} \mathrm{C}$ shows the formation of a pore in the upper grain.

The general morphology of this system was directly compared to that reported by Nkou Bouala et al. ${ }^{34}$ who recorded in situ HT-ESEM images series on $250 \mathrm{~nm}$ diameter grains systems to observe the morphological variations occurring during a heat treatment at $1275^{\circ} \mathrm{C}$ at the microscopic scale. This study evidenced that the number of crystallites present in the grains decreased during the heat treatment, while necks formed concomitantly and grew regularly with time. Meanwhile, an exaggerated growth of a crystallite located in the neck region was systematically observed at the end of the first stage of sintering.

In the case of the nanospheres investigated in the present study, the images in Figure 3 clearly demonstrate that two sintering processes occurred concomitantly in the two-grain systems. The first one took place within the grains and corresponds to the sintering and growth of the elementary crystallites (i.e. to the decrease of the crystallites number in each grain), while the other led to the 
formation and the development of a neck between the two grains. One can also observe the formation then the elimination of a pore between $\mathrm{T}=800^{\circ} \mathrm{C}$ and $950^{\circ} \mathrm{C}$ (shown by the white arrow in Figure 3). This pore, which was observed as a white zone in the center of the upper grain, was present at $800^{\circ} \mathrm{C}$ and $900^{\circ} \mathrm{C}$. Finally, when the temperature increased from $900^{\circ} \mathrm{C}$ to $950^{\circ} \mathrm{C}$, the morphology of the grains turned from a spherical to a cubic shape, as already described before.

Even if the thermal treatments were not strictly identical, and despite the difference in the particles diameter (i.e. $50 \mathrm{~nm}$ vs $250 \mathrm{~nm}$ ), the general behavior of the $\mathrm{ThO}_{2}$ particles appeared to be very similar when observed by HT-ESEM and HT-HRTEM. The nanoscale particles used in the present study then presented exactly the same behavior than their micrometric counterparts, and can be considered to be representative for real powders used in the fabrication of oxide ceramics.

\section{Observations at the crystallite scale}

When observing the sample at higher magnification, information was available down to the crystallite scale. The image series reported in Figure 4 is a magnification of the edge of the upper grain that is included in the white rectangle shown on the first image of Figure 3. This image series allowed a local and step-by-step description of sintering.

In this zone, the shape of four crystallites are underlined in the first image recorded at $\mathrm{T}=55^{\circ} \mathrm{C}$. When temperature increased, the orientations of these crystallites relative to the electron beam direction and the crystallographic orientations of the grains were observed. As instance, the red crystallite was not observed at low temperature but became clearly visible when the temperature rose up to $77^{\circ} \mathrm{C}$. Afterwards, its orientation remained stable up to $428^{\circ} \mathrm{C}$. The blue crystallite was observable from time to time, with different crystallographic orientations, indicating that this latter was changing continuously during the heat treatment up to $328^{\circ} \mathrm{C}$. This was also the case for the yellow and green crystallites. Some modifications in the orientations were observed up to $300^{\circ} \mathrm{C}$ and occurred very fast. Indeed, some of these rotations were found to happen between two consecutive images, i.e. within a 
143 ms frame rate. Below $300^{\circ} \mathrm{C}$, the edges of the crystallites remained unchanged. Only the plane orientation was modified between the two images. This process is very similar to the oriented attachment mechanism that was used to describe the organization of nanometric crystals in liquids ${ }^{48}$.

To our knowledge, if such a process was already reported to describe the reorganization of ceramic nanocrystallites at high temperature ${ }^{10}$, it is the first time that it is directly observed as it was already done for metallic nanoparticles ${ }^{49-51}$.

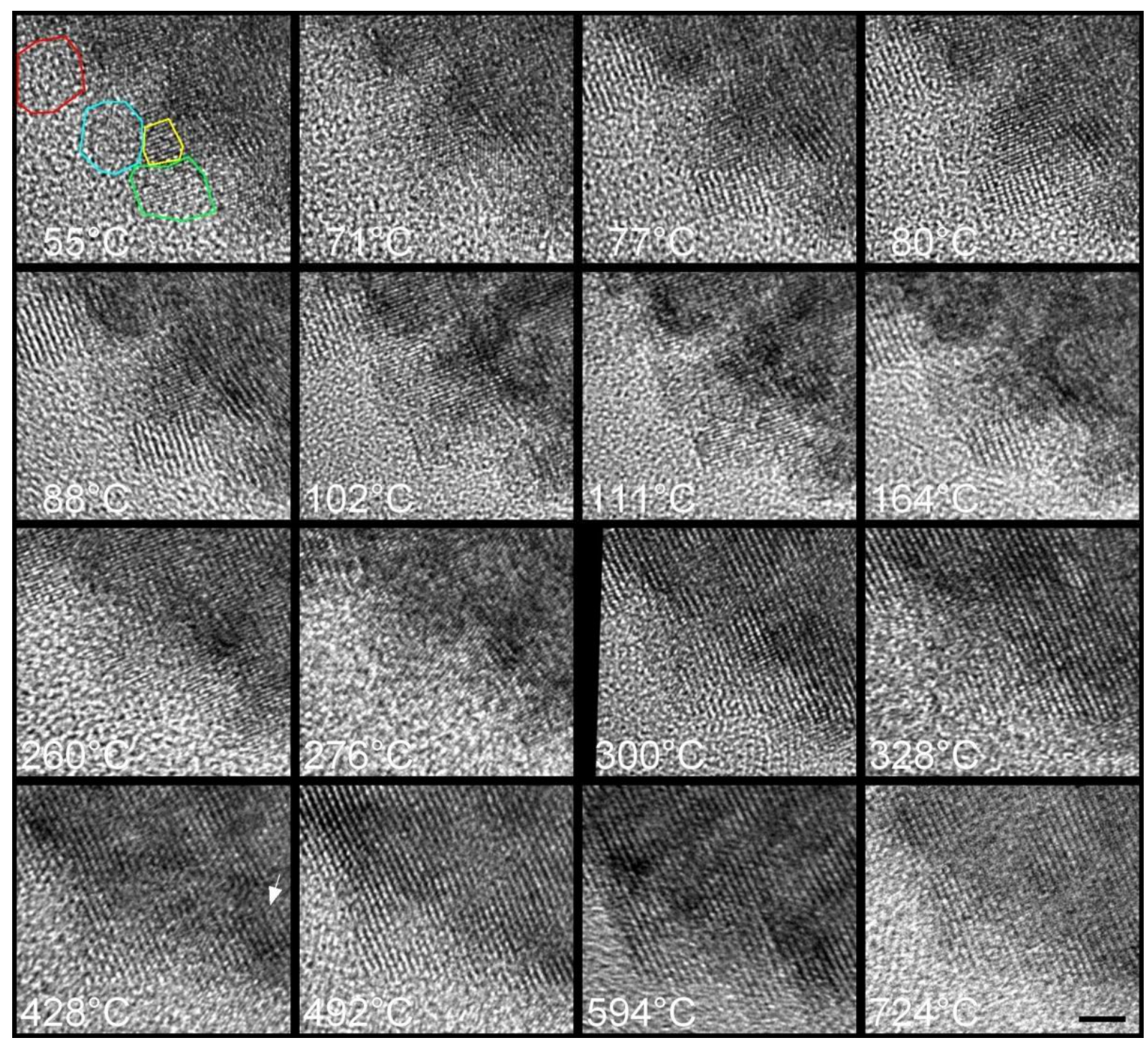




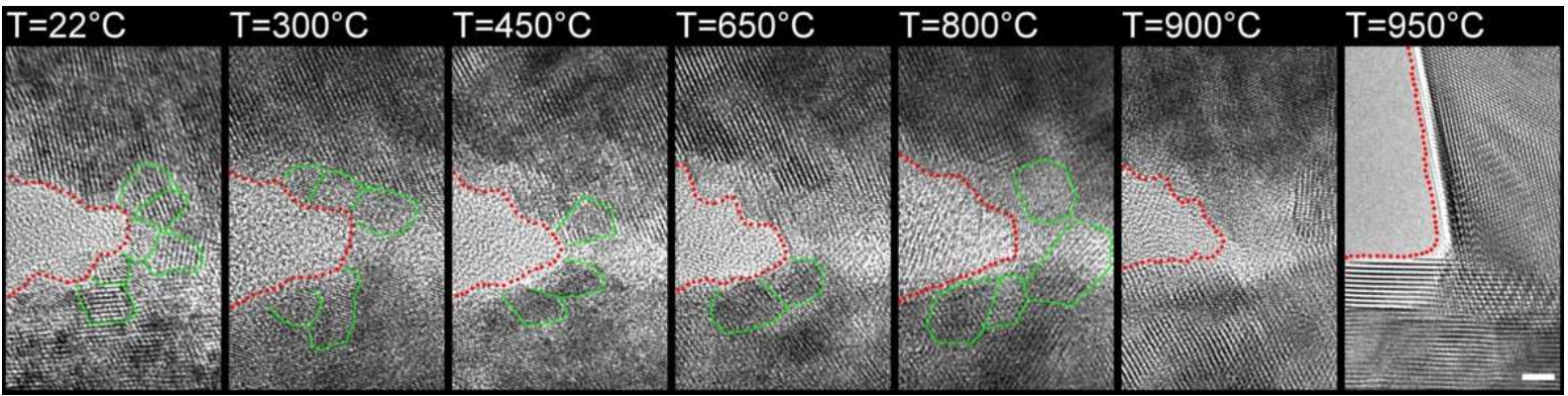

Figure 4. a) HT-HRTEM images recorded at different temperatures and at high magnification during in situ heating of a two grains system of $50 \mathrm{~nm}$ in diameter showing the morphological modifications occurring at the edge of the upper grain. This zone corresponds to the white rectangle reported on the first image of Figure 3. b) Lower magnification images showing the evolution of the neck during the heat treatment (scale bars $=2 \mathrm{~nm}$ ). See Supplementary Files 54 and 55 for the complete movies.

Above $300^{\circ} \mathrm{C}$, all the crystallites observed in this zone adopted a unique crystallographic orientation. However, point defects remained present in the grains as underlined in the image recorded at $428^{\circ} \mathrm{C}$, where the white arrow (Figure 4) indicated the presence of an additional atomic column. Even if these local defects moved when the temperature increased, this nanostructure, made of oriented domains with walls containing point defects, remained observable up to $724^{\circ} \mathrm{C}$.

In the zone of contact between the two grains (Figure 4b), crystallites can be hardly attributed to the upper or to the lower grain, and they can be considered to be shared between both grains, as already reported in Figure 1. At RT, the point-contact between the two grains was formed by numerous crystallites that have no chemical nor physical bonding. The misorientation between the crystallites that are observed in each grain is obvious (Figure 4b). When the temperature increased up to $300^{\circ} \mathrm{C}$, the crystallites were re-oriented one in relation to each other as already described previously (see the crystallites outlined in green in Figure 4b). Surprisingly, the neck between the grains was already formed even for temperatures as low as $300^{\circ} \mathrm{C}$. As crystallites located between the grains were already in contact at RT, they rotated to accommodate misorientation, and then formed the first physical link between the two grains. The reorientation of the crystallites yielded to crystallite growth when increasing the temperature. The grain boundary, which was clearly observed at $950^{\circ} \mathrm{C}$, corresponded to a misorientation between the general orientations of the crystallites in each grain. 

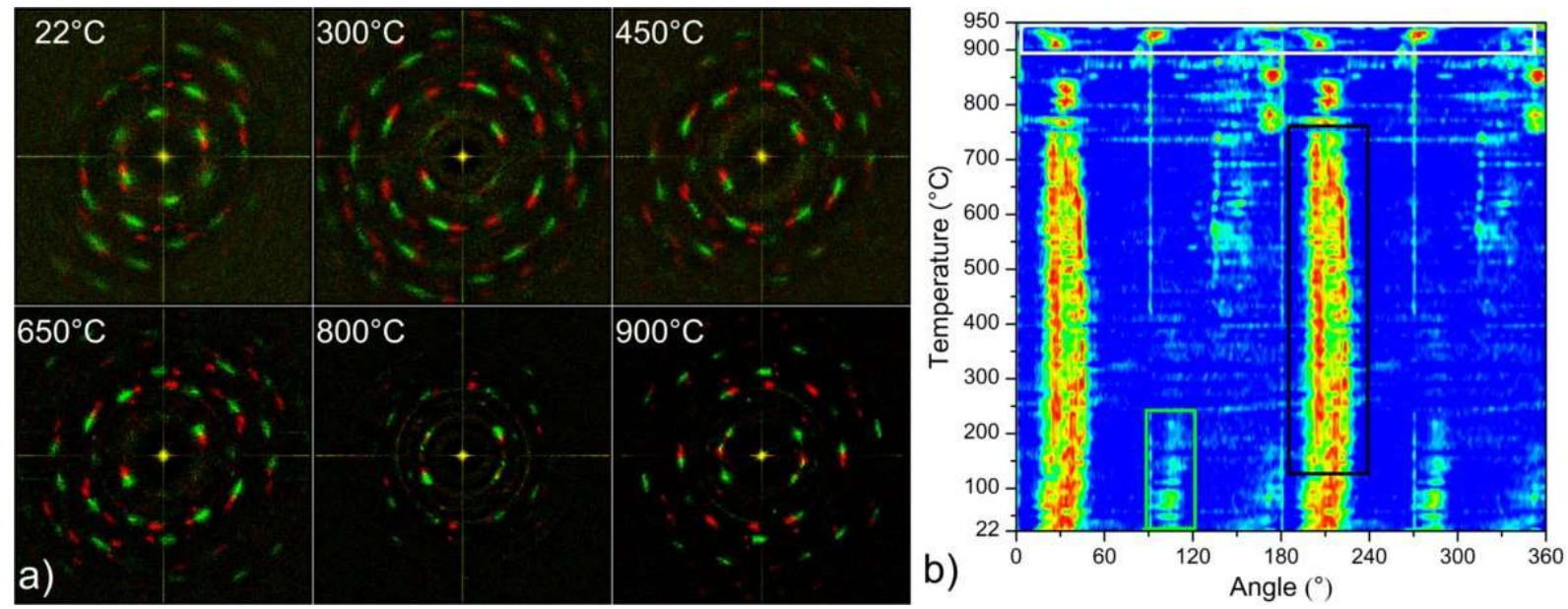

Figure 5. Processing of the FFT patterns determined from the HT-HRTEM images recorded on the 50nm two grains system shown in Figure 3. The red and green dots correspond to the diffraction spots of the upper and lower grain respectively. a) FFT patterns obtained on the complete system at $22^{\circ} \mathrm{C}, 300^{\circ} \mathrm{C}, 450^{\circ} \mathrm{C}, 650^{\circ} \mathrm{C}, 800^{\circ} \mathrm{C}$ and $900^{\circ} \mathrm{C}$. b) Diagram showing the positions and the intensities of the 200 diffraction spots as a function of temperature. Several domains are identified for discussion.

As HRTEM micrographs were recorded, FFT patterns were calculated on limited areas of the images in order to determine the average crystallographic orientation of the crystallites in each grain, according to the image processing described in the Methods section and reported as Supplementary File S6. The FFT patterns obtained for the two-grain system at RT, $300^{\circ} \mathrm{C}, 450^{\circ} \mathrm{C}, 650^{\circ} \mathrm{C}, 800^{\circ} \mathrm{C}$ and $900^{\circ} \mathrm{C}$ are reported in Figure $5 \mathrm{a}$, while the representation built from the series of FFT patterns is reported in Figure 5b. The FFT pattern obtained at RT presents the characteristic diffraction spots of a polycrystalline sample. The misorientation angle was evaluated to approximately $5^{\circ}$ around the main [200] direction. Thus, at room temperature, the grains were formed of crystallites that were slightly tilted one with respect to the others inside each grain. Furthermore, the FFT pattern recorded at room temperature showed that both grains presented the same general orientations, even if they were misoriented. Furthermore, the 200 diffraction spot was observed for the upper grain while both 200 and 020 diffraction spots were observed for the lower grain. This second spot is underlined in green in Figure $5 \mathrm{~b}$. When the system was heated up to $200^{\circ} \mathrm{C}$, the FFT pattern of the lower grain only presented 
the 200 diffraction spot (as the diffraction spot located at about $100^{\circ}$ disappeared, Figure $5 \mathrm{~b}$, green frame), which clearly illustrated that a fast reorganization of crystallite orientations occurred at low temperature (typically in the $100-200^{\circ} \mathrm{C}$ temperature range). Such structural modifications were also observed in Figure $5 b$ by looking at the signal centered at $210^{\circ}$ (black frame). Here, the (200) planes tended to form 2 separated spots, each spot corresponding to one grain. This characterized the crystallites reorganization occurring inside each grain, as already observed in the HT-HRTEM images.

This reorganization, i.e. orientation of crystallites in a common direction within each grain, can be directly observed on the FFT patterns obtained at $450^{\circ} \mathrm{C}$ and $650^{\circ} \mathrm{C}$ (Figure $5 \mathrm{a}$ ), where the diffraction spots corresponding to the upper and the lower grains are represented in red and green, respectively. The diffraction spots become punctual while temperature increases from 100 and $750^{\circ} \mathrm{C}$ (black rectangle in Figure $5 b)$. This corresponds to an increase of the crystallites ordering, as all the crystallites tend to adopt a unique crystallographic orientation within a grain. This indicates that the misorientation of the crystallites decreases in each grain, which is consistent with previous findings from HT-HRTEM images. However, the two grains remained misoriented one with respect to the other by approximately $15^{\circ}$ at $\mathrm{T}=700^{\circ} \mathrm{C}$

Above $780^{\circ} \mathrm{C}$, the angular positions of the 200 diffraction spots appeared to be quickly modified, indicating that there was a strong and fast modification of grains (Figure 5b). In this range of temperature, the 200 diffraction spots for each grain were located at different angular positions, which resulted from the rotation of one grain relative to the other one. The angular variation was approximately $10^{\circ}$. The rotation of the grains during the first stage of sintering has been already reported during studies devoted to the sintering of Cu metal spheres using X-ray tomography analyses ${ }^{29,52}$ or during the study of $\mathrm{ZrO}_{2}$ monocrystalline grains sintering ${ }^{18}$. The authors indicated that the driving force for such a reorganization was the minimization of the surface energy in the system. The maximum rotation amplitude reported in these studies was $20^{\circ}$, which is in good agreement with the value determined in this work. This mechanism, which is important to explain the grain rearrangement 
inside the solids at high temperature, is herein observed directly for ceramic-type particles. The present study then confirm the observations made by Rankin ${ }^{14}$ and proved that the grain reorientation also occurs in ceramic materials prior to grain growth. The driving force seemed to be related with the minimization of the contact energy between the two grains in the neck region.

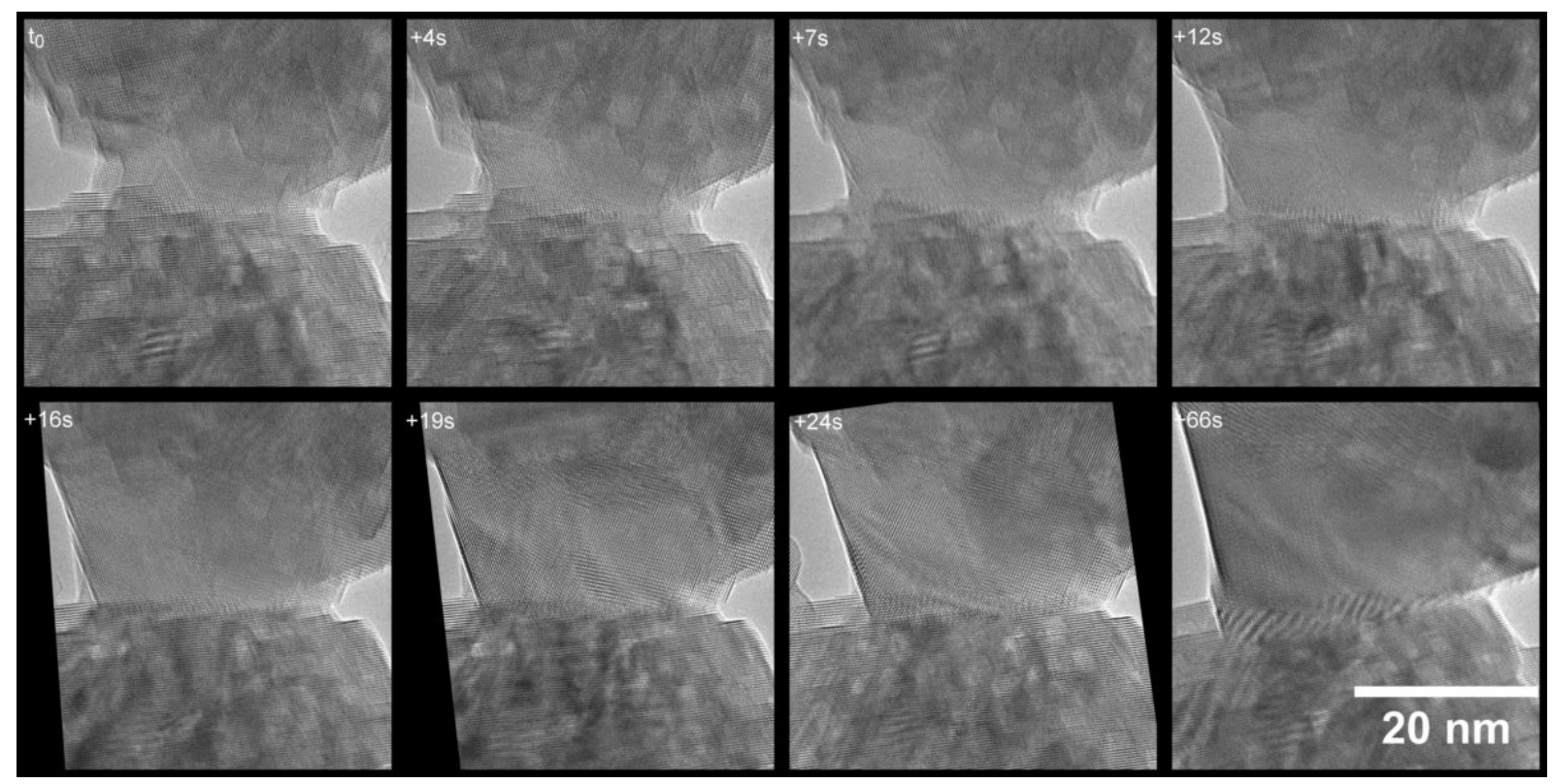

Figure 6. HT-TEM image series recorded at $T=950^{\circ} \mathrm{C}$ on a two grains system showing the morphological modifications occurring on the upper grain and on the neck region (see Supplementary File S7 for the complete movie).

At $\mathrm{T}=950^{\circ} \mathrm{C}$, the $\mathrm{FFT}$ patterns became unusable as the recrystallization of the $\mathrm{SiN}_{1-\mathrm{x}}$ membrane induced the formation of additional diffraction spots superimposed to those of $\mathrm{ThO}_{2}$. However, as already described in the previous section, important transformations were observed at the grain scale, particularly in the upper grain and close to the neck. Indeed, even if the grains were already almost single crystals at $900^{\circ} \mathrm{C}$ when looking at the FFT pattern (Figure 5a), an important reorganization occurred in the upper grain at $950^{\circ} \mathrm{C}$ within a limited time (only 66 seconds from the beginning to the end of the transformation). From a morphological point of view, the transformed zone seemed to become a single crystal and the edge between the raw and transformed zone was easily identified, as there seems to be no crystallites in the transformed region (Figure 6). This transformation was associated to a very slight reorganization of the crystallites, leading to the elimination of stacking faults. 
As the transformation seemed to begin within the neck zone to finally propagate in the grain itself, one can suggest that an important rearrangement took place at the boundary between the two grains. The recovered energy was probably low, but sufficient enough to cause further significant changes step by step. In the present experiment, the transformation stopped before the grain turned completely into a single crystal. A supplementary energy barrier (maybe due to a high concentration of stacking faults that have been dragged during the transformation or to a high concentration of dislocations that forms walls or to dislocations that encounter point defects that stop their movement...) might have stopped the propagation of the transformation. However, the formation of a single crystal still remains the most stable configuration for the grain at higher temperature. Indeed, as reported in Figure 2, both grains became totally and perfectly monocrystalline after heating at $1025^{\circ} \mathrm{C}$, even if they did not share the same crystallographic orientation at the end of the experiment. Such a transformation has already been described by Nkou Bouala et al. during the in situ study of the first stage of sintering of $\mathrm{ThO}_{2}$ by HT-ESEM ${ }^{34}$.

Also, it is important to point out that this process has been observed three times during our experiment (at $\mathrm{T}=950^{\circ} \mathrm{C}$ ). Indeed, at the end of this experiment, the morphology of other two-grain systems that have never been exposed to the electron beam illumination, has been checked. In these systems, the sintering (formation and growth of a neck between the two grains) also proceeded although the formation of monocrystalline domain was not observed in the neck region. A few seconds after the sample irradiation by the electron beam, such a transformation was finally observed, as previously described.

\section{Growth of the neck between the 2 grains}

At $950^{\circ} \mathrm{C}$, as the grains are monocrystalline, the plane that forms the contact between the two grains is the grain boundary as defined by Coble ${ }^{30}$. Consequently, the classical laws describing the first stage of sintering, i.e. neck growth between two single crystalline particles, can be considered. The 
diameter of the neck increased from $17( \pm 0.5) \mathrm{nm}$ to $32( \pm 0.5) \mathrm{nm}$ in only 2 minutes. From the set of images, the evolution of the sintering degree, $\lambda$, defined as the ratio between the neck $(x)$ and grain $(r)$ diameters was followed at $950^{\circ} \mathrm{C}$ (Figure 7). It was fitted using the classical equation developed for a two monocrystalline grains system, according to Eq. 1:

$$
\lambda^{n}=\frac{k \cdot t}{r^{m}}
$$

where $\lambda=x / r$ denotes the sintering degree, $\mathrm{k}$ is the kinetic constant, $\mathrm{t}$ is the duration of heat treatment, and $\mathrm{n}$ and $\mathrm{m}$ are exponents characteristic of the diffusion process involved (i.e. mainly surface, volume or grain boundary diffusion).

As the grain diameter remained constant at $950^{\circ} \mathrm{C}$ (in a first approximation) and close to 50 $\mathrm{nm}$, the $\mathrm{r}^{\mathrm{m}}$ term was considered to be almost unchanged, which led to the definition of an apparent kinetic constant $k^{\prime}$ such as :

$$
\lambda=\left(\frac{k \cdot t}{r^{m}}\right)^{1 / n}=\left(k^{\prime} \cdot t\right)^{1 / n}
$$

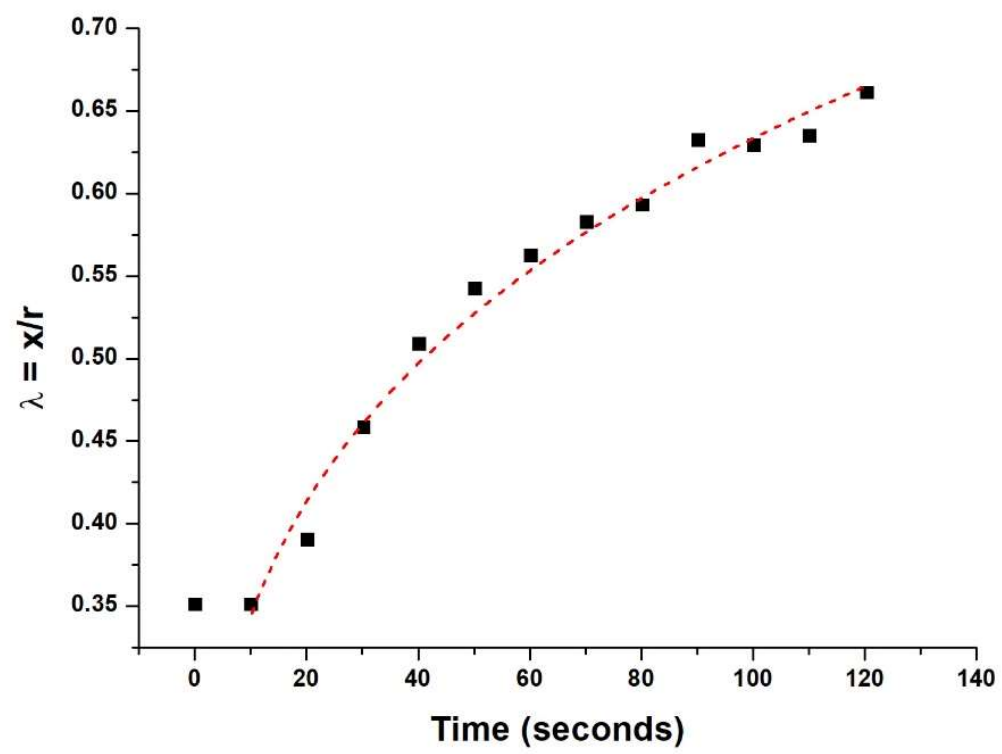

Figure 7. Evolution of the sintering parameter $\lambda$ obtained at $T=950^{\circ} \mathrm{C}$ from $H T$-HRTEM images on $\mathrm{ThO}_{2}$ nanospheres of 50 $n m$ in diameter. 
As explained above, the $n$ value was used to identify the main mechanism driving sintering, with $n$ $=2$ accounting for viscous flow; $\mathrm{n}=3$ for evaporation-condensation; $\mathrm{n}=4$ for volume diffusion; $\mathrm{n}=6$ for grain boundary diffusion and $\mathrm{n}=7$ for surface diffusion. In our study, fitting the experimental data obtained at $950^{\circ} \mathrm{C}$ led to $\mathrm{n}=3.8 \pm 0.2$, thus indicating that the neck elaboration mostly processed through volume diffusion. This result complements the findings of Nkou Bouala et al. who reported a value of $n=6$ from HT-ESEM observations performed at higher temperature (i.e. between 1175 and $1300^{\circ} \mathrm{C}$ ) using bigger particles (typically around $250 \mathrm{~nm}$ in diameter) ${ }^{34}$. In our case, the process imaged corresponds to the early formation of a neck between the particles, which obviously cannot proceed through grain boundary diffusion, as this latter is not formed at $t=0$. Once the neck initiated and partially developed, and once the grain boundary defined following the alignment of crystallites within both grains, grain boundary diffusion can be activated, which corresponds to the phenomena observed by Nkou Bouala et al. Also, it is important to note that both diffusion paths (i.e. volume and grainboundary diffusion) led to the sample densification and to close microstructural evolutions.

\section{Observations at the atomic scale}

To go further into the description of the first step of $\mathrm{ThO}_{2}$ sintering, HT-HRTEM images were recorded in the neck region at $\mathrm{T}=950^{\circ} \mathrm{C}$ (Figure 8a). As described previously, the grain boundary between the two grains corresponds to a misorientation of both grains. When expanding the heat treatment at $\mathrm{T}=950^{\circ} \mathrm{C}$, atoms diffused to the neck surface and a fast reorganization of the atomic planes was observed within the same crystallographic orientation. The kinetic of the grain boundary displacement by atomic column additions was estimated by quantifying the motion of the atom front plane (Figure 8b). The motion of the front plane within a single crystal was found to be linear with time. The derived motion rate was close to $1 \mathrm{~nm} \cdot \mathrm{s}^{-1}$, which corresponds to the addition of approx. 4 atomic columns per second to the neck. 

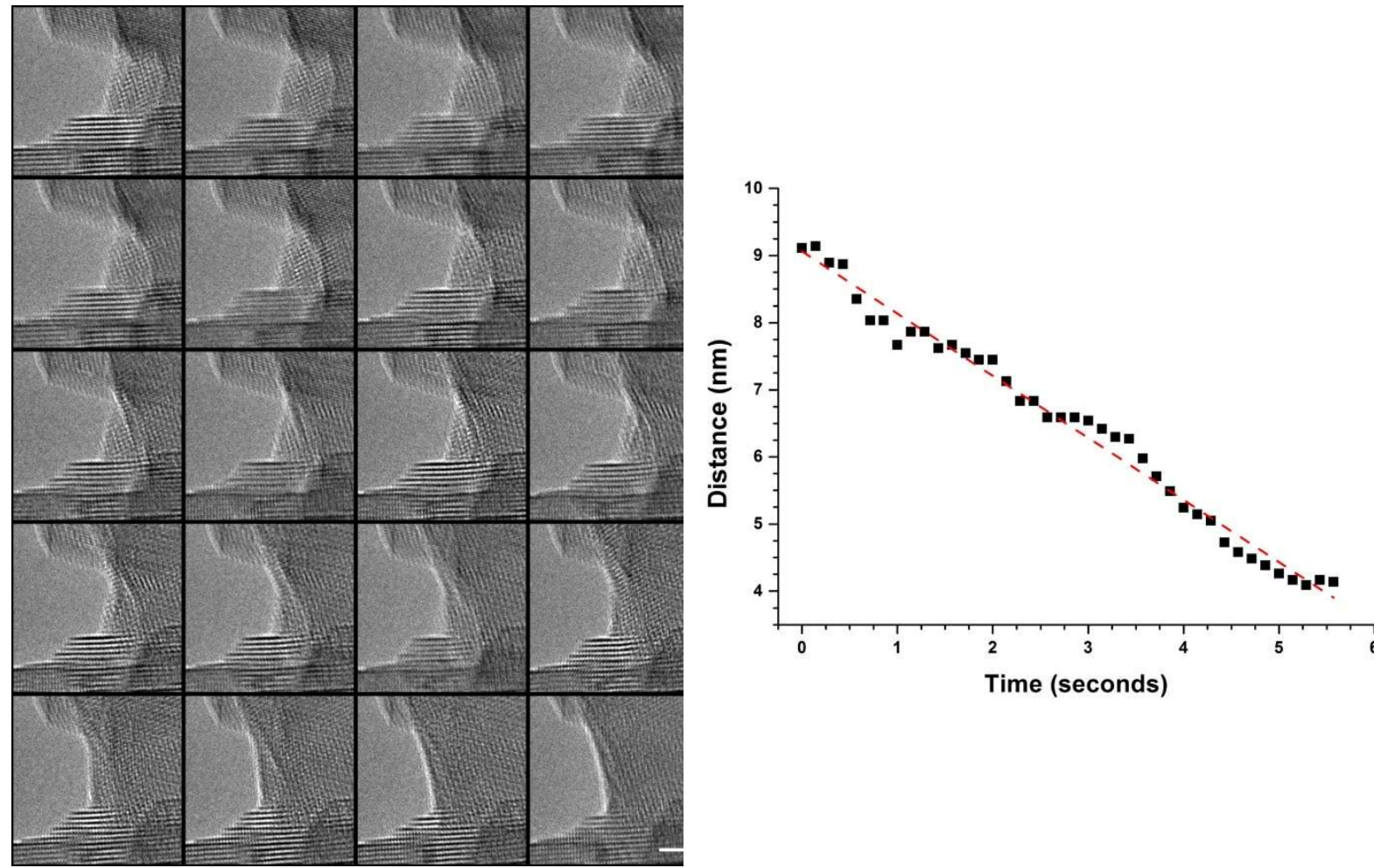

Figure 8.a) HT-TEM Image series recorded at $950^{\circ} \mathrm{C}$ on a two polycrystalline spheres system (see Supplementary File S8 for the complete movie). The delay between two images was 2/7 second (Scale bar $=2 \mathrm{~nm}$ ). The image series must be read from left to right and from top to bottom. b) Variation of the position of the front plane with time.

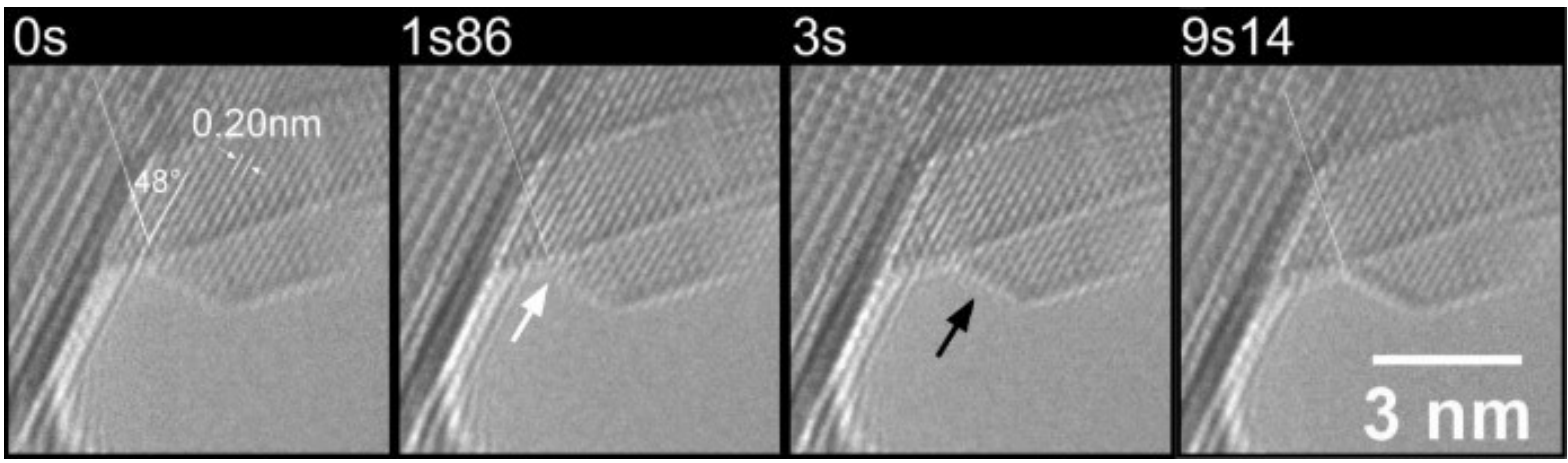

Figure 9. HT-HRTEM images of the grain boundary showing the motion of atomic columns. Interplanar spacing in the crystallite of interest and misorientation between to neighboring crystallite are shown on the first image. The black and white arrows indicate the moving plane (see Supplementary File 59 for the complete movie). 
Another zone of the neck, corresponding to the opposite side of the upper grain was also studied. In this region, no fast transformation occurred during the experiment. One particular crystallite, where the (200) planes were observable remained misoriented compared to the others in the grain. Such a configuration in the upper grain might result from the fast transformation described before, for example from the formation of walls due to the concentration of dislocations. Snapshots of the $1 / 7 \mathrm{~s}$ movie recorded in this region (Supplementary File S9) are gathered in Figure 9 . They show motions of atoms and atomic columns. The displacement of atom columns was evidenced by comparing the four images. It corresponded to a fast process, which occurred within a $0.15 \mathrm{~s}$ delay (the moving plane is indicated in Figure 9 by white and black arrows). However, the time between two displacements lasted up to a few seconds. During this delay, the structure was stable and no diffusion was observed at the atomic scale (even at $950^{\circ} \mathrm{C}$ ). In this case, the motion rate of the grain border was lowered to $0.1 \mathrm{~nm} \cdot \mathrm{s}^{-1}$, which was ten times slower than that determined for the atomic column motion within the same crystallographic orientation. Such a result suggests that misorientations between the crystallites were able to slow down or stop the recrystallization processes.

\section{Discussion}

From a polycrystalline to a single-crystal grain

From the observations reported above, a multi-step mechanism describing the reorganization of the crystallites within a grain during a heat treatment at high temperature was proposed. First, the characterization of the starting material showed that the crystallites forming the nanospheres were not randomly oriented. They all shared a common orientation, yet with a small angle of misorientation. Second, the reorganization of the crystallites within a single grain occurred between RT and $300^{\circ} \mathrm{C}$. This yielded the disorientation angle to decrease between the crystallites when temperature was higher than $100^{\circ} \mathrm{C}$. The underlying driving force is probably the minimization of the surface free energy of the nanoparticles in the grain ${ }^{53,54}$. This reorganization was achieved by a slight rotation of 
nanocrystallites one with respect to the others, so that a coherent combination of their crystalline planes could occur. This mechanism is close to the oriented attachment mechanism described for the growth of crystallites in solution ${ }^{27}$ or at high temperature ${ }^{8}$. With the $50 \mathrm{~nm}$ diameter $\mathrm{ThO}_{2}$ nanospheres made of 3-5 nm crystallites used in the present study, this reorganization was observed up to $300^{\circ} \mathrm{C}$. Nevertheless, it was not reported during the sintering of $\mathrm{UO}_{2}$ (3-5 nm diameter) or $\mathrm{ThO}_{2}$ (19 $\mathrm{nm}$ size) nanoparticles ${ }^{55}$ that were initially isolated ${ }^{56}$. In the case of $3-5 \mathrm{~nm} \mathrm{CeO}$ nanoparticles sintering, Cordeiro and Leite ${ }^{22}$ have shown that even if the sintering onset was delayed up to $870^{\circ} \mathrm{C}$ (due to the presence of organics at the surface of the nanoparticles that turned into an amorphous carbon layer at high temperature and stabilize the NPs), nanoparticle rotations were observed. This yielded to the reorientation of the crystallographic planes and to a fast growth mechanism of the nanoparticles close to the mechanism observed in this study. These authors noted that a neck between the nanoparticles was effectively formed after this reorientation.

Above $300^{\circ} \mathrm{C}$, the crystallites were mainly reorganized and aligned along a main crystallographic orientation in the grain. The walls of the domains were made by concentrated point defects that migrated with increasing temperature. Their concentration resulted in the formation of a pore in the upper grain observed at $800^{\circ} \mathrm{C}$. The elimination of this pore then occurred between 900 and $950^{\circ} \mathrm{C}$, probably through a volume diffusion mechanism driving the matter from the grain center to the neck. Simultaneously, the size of the crystallites still increased up to $950^{\circ} \mathrm{C}$.

Finally, for $\mathrm{T} \geq 950^{\circ} \mathrm{C}$, the crystallites present in the grain had the same crystalline orientation. However, boundaries probably remained present between the crystallites in the form of high defects concentration zones. A slight temperature increase (or illumination by the electron beam) brought sufficient energy to eliminate the last point defects or dislocation walls present between the crystallites. This process was fast and yielded to the formation of a single crystal. The $50 \mathrm{~nm}$ diameter grain then became monocrystalline and finally adopted a cubic shape. 
Formation of the neck

On the selected systems, a point of contact was observed as soon as the two grains were deposited on the $\mathrm{SiN}_{1-\mathrm{x}}$ layer, and appeared to be formed by the outer crystallites present in both grains. However, this contact was not consolidated at room temperature. When temperature increased, the neck was consolidated by the oriented attachment mechanism that yielded to the growth of the crystallites present in the region of the neck ${ }^{57}$. Even if the crystallites exhibited similar crystallographic orientations in the grain, those located in the neck region were not specifically oriented. Both grains could then detach as the neck was not sufficiently consolidated, i.e. up to 300$400^{\circ} \mathrm{C}$.

Above $400^{\circ} \mathrm{C}$, the crystallites in the region of the neck were reoriented with respect to the main crystallographic planes in one grain. In these conditions, the neck was physically formed and consolidated. The grain boundary corresponded to the plane of crystallographic disorientation between the two grains. The large number of crystallites that are present in the zone of the neck was expected to increase the growth rate of the neck ${ }^{31}$. However, up to $950^{\circ} \mathrm{C}$, only the growth of crystallites was visible on the HT-HRTEM images (Figure 4b) and the growth of the neck size was not obvious. Thus, a temperature lower than $950^{\circ} \mathrm{C}$ is not high enough to induce the growth process of the neck.

At $950^{\circ} \mathrm{C}$, i.e. after the grains turned to single crystals, the grain boundary was clearly observed in the images (Figure 6). It separated both grains that had two distinct crystallographic orientations. The disorientation between the grains was not eliminated while pursuing the heat treatment and the grain boundary (which is the neck) remained stable with time. The growth of the neck was mainly associated to matter transport from the bulk of the grain to the neck and was clearly associated to the grain transformation into a single crystal (Figure 8). The presence of misoriented crystallites in the grain decreased the neck growth rate. This finding is in good agreement with the results reported by Cordeiro et al. ${ }^{22}$. If one grain rotated relative to the other in order to recover the same crystallographic 
orientation, the grain boundary was eliminated and the neck grew faster. This mechanism, which was observed for small nanoparticles ${ }^{8}$ was probably too energetically consuming for grains as large as those used in the present study (50 $\mathrm{nm}$ diameter).

\section{Conclusions}

High Temperature and High Resolution TEM observations were used for the first time to image the early processes leading to the formation of necks between the grains during the sintering of oxide ceramics, herein $\mathrm{ThO}_{2}$ polycrystalline particles. High spatial and time resolutions offered by HT-HRTEM led us to distinguish several successive steps giving birth to grain boundaries that rely on morphological modifications from the atomic scale to the grain scale.

First, observations of $50 \mathrm{~nm}$-diameter $\mathrm{ThO}_{2}$ spherical particles prepared by wet chemistry methods revealed that the crystallites constituting the grains were not randomly oriented, but shared a common orientation following self-assembly in solution. As such, the starting material still differed from the single crystals generally considered in numerical models, but cannot be described as a fully disordered polycrystalline assembly.

Upon heating, rearrangement of crystallites first occurred within each grain. This process was mainly driven by oriented attachment at low temperature and led to the growth of crystallites. At high temperature (typically above $900^{\circ} \mathrm{C}$ ), the elimination of the remaining defects yielded the formation of single crystals. This modification of the inner microstructure of the grains was also found to impact the nature of the contact between the grains, which pre-exists at room temperature then progressively evolve to form a neck. At low temperature, it is constituted by numerous crystallites that can be considered to be shared between both grains, and then significantly differs from the usual representation of the grain boundary reported in the literature and used in the numerical models. Such a state-of-the-art grain boundary was only obtained following the reorientation of the crystallites at 
high temperature, and corresponds to the plane of disorientation between the two grains. The growth of the neck finally proceeds by atomic displacements. These latter were faster (and seemed favored) when the grains were monocrystalline.

All these findings showed that the initial stage of sintering, dedicated to the formation and the growth of necks between the grains, is strongly governed by the behavior of elementary crystallites. Monitoring their size/morphology and self-assembly processes during the synthesis then appears as a key challenge to improve the sintering ability of ceramic powders. Also, their prevailing role in the first instants of the densification process underlines the need to consider polycrystalline materials in numerical models. As such, advanced microscopic techniques allowing in situ observations with high time and space resolution should be considered as a tool of choice to collect new information and quantitative data for the update or development of future sintering models.

\section{Conflict of interest}

There are no conflicts to declare.

\section{Author contributions'}

R. Podor: Investigation / Writing - original draft

V. Trillaud: Investigation

G.I. Nkou Bouala: Investigation

N. Dacheux: Writing - review \& editing

C. Ricolleau: Investigation / Writing - review \& editing

N. Clavier: Project administration / Writing - review \& editing 


\section{Acknowledgments}

The authors acknowledge financial support from the CNRS-CEA "METSA" French network (FR CNRS 3507) for the TEM experiments conducted on the MPQ (Université de Paris) platform. 


\section{References}

1. R. K. Bordia, S. J. L. Kang and E. A. Olevsky, J Am Ceram Soc, 2017, 100, 2314-2352.

2. G. Okuma, D. Kadowaki, T. Hondo, S. Tanaka and F. Wakai, Sci Rep, 2017, 7, 11106.

3. S. Deville and A. J. Stevenson, J Am Ceram Soc, 2015, 98, 2324-2332.

4. F. Wakai, J Am Ceram Soc, 2006, 89, 1471-1484.

5. S. Bordere and D. Bernard, Comp Mater Sci, 2008, 43, 1074-1080.

6. S. Martin, R. Parekh, M. Guessasma, J. Lechelle, J. Fortin and K. Saleh, Powder Technol, 2015, 270, 637-645.

7. M. A. Asoro, D. Kovar, Y. Shao-Horn, L. F. Allard and P. J. Ferreira, Nanotechnology, 2010, 21, 025701.

8. M. Jose-Yacaman, C. Gutierrez-Wing, M. Miki, D. Q. Yang, K. N. Piyakis and E. Sacher, J Phys Chem B, 2005, 109, 9703-9711.

9. A. Kocjan, M. Logar and Z. J. Shen, Sci. Rep., 2017, 7, 2541.

10. G. I. Nkou Bouala, N. Clavier, J. Lechelle, A. Mesbah, N. Dacheux and R. Podor, Ceram Int, 2015, 41, 14703-14711.

11. G. I. Nkou Bouala, N. Clavier, S. Martin, J. Lechelle, J. Favrichon, H. P. Brau, N. Dacheux and R. Podor, J Phys Chem C, 2016, 120, 386-395.

12. A. Casu, A. Genovese, L. Manna, P. Longo, J. Buha, G. A. Botton, S. Lazar, M. Upadhyay, U. Schwingenschlogl, M. Prato, H. B. Li, S. Ghosh, F. Palazon, F. De Donato, S. L. Mozo, E. Zuddas and A. Falqui, Acs Nano, 2016, 10, 2406-2414.

13. Y. Q. Dai, P. Lu, Z. M. Cao, C. T. Campbell and Y. N. Xia, Chem Soc Rev, 2018, 47, 4314-4331.

14. M. A. Asoro, D. Kovar and P. J. Ferreira, Chem Commun, 2014, 50, 4835-4838.

15. W. Albrecht, A. van de Glind, H. Yoshida, Y. Isozaki, A. Imhof, A. van Blaaderen, P. E. de Jongh, K. P. de Jong, J. Zecevic and S. Takeda, Ultramicroscopy, 2018, 193, 97-103.

16. Y. Zhang, S. Bals and G. Van Tendeloo, Part Part Syst Char, 2019, 36, 1800287.

17. H. Nakayama, M. Nagata, H. Abe and Y. Shimizu, Catalysts, 2021, 11, 19.

18. J. Rankin, J Am Ceram Soc, 1999, 82, 1560-1564.

19. C. R. Xue, T. Narushima, Y. Ishida, T. Tokunaga and T. Yonezawa, Acs Appl Mater Inter, 2014, 6, 19924-19932.

20. A. Casu, A. Lamberti, S. Stassi and A. Falqui, Nanomaterials-Basel, 2018, 8, 40.

21. H. Majidi, T. B. Holland and K. van Benthem, Ultramicroscopy, 2015, 152, 35-43.

22. M. A. L. Cordeiro and E. R. Leite, Cerâmica, 2015, 61, 269-275.

23. R. L. Penn and J. F. Banfield, Science, 1998, 281, 969-971.

24. E. Longo, W. Avansi, J. Bettini, J. Andres and L. Gracia, Sci. Rep., 2016, 6, 21498.

25. Y. Tian, W. Jiao, P. Liu, S. X. Song, Z. Lu, A. Hirata and M. W. Chen, Nat Commun, 2019, 10, 5249.

26. A. P. Lange, A. Samanta, H. Majidi, S. Mahajan, J. Ging, T. Y. Olson, K. van Benthem and S. Elhadj, Acta Mater, 2016, 120, 364-378.

27. W. Q. Lv, W. D. He, X. N. Wang, Y. H. Niu, H. Q. Cao, J. H. Dickerson and Z. G. Wang, Nanoscale, 2014, 6, 2531-2547.

28. B. Kieback, M. Noethe, R. Grupp, J. Banhart, T. Rasp and T. Kraft, J Mater Sci, 2012, 47, 70477055.

29. S. A. McDonald, C. Holzner, E. M. Lauridsen, P. Reischig, A. P. Merkle and P. J. Withers, Sci. Rep., 2017, 7, 5251.

30. R. L. Coble, J Am Ceram Soc, 1958, 41, 55-62. 
31. M. K. Kini and A. H. Chokshi, Materialia, 2020, 10, 100665.

32. K. Anantharaman, V. Shivakumar and D. Saha, J Nucl Mater, 2008, 383, 119-121.

33. M. Gabard, Y. Cherkaski, N. Clavier, L. Brissonneau, M. C. Steil, J. Fouletier, A. Mesbah and N. Dacheux, J Alloy Compd, 2016, 689, 374-382.

34. G. I. Nkou Bouala, N. Clavier, J. Lechelle, J. Monnier, C. Ricolleau, N. Dacheux and R. Podor, J Eur Ceram Soc, 2017, 37, 727-738.

35. L. Wang, R. Zhao, X. W. Wang, L. Mei, L. Y. Yuan, S. A. Wang, Z. F. Chai and W. Q. Shi, Crystengcomm, 2014, 16, 10469-10475.

36. R. G. Spruit, J. T. van Omme, M. K. Ghatkesar and H. H. P. Garza, J Microelectromech S, 2017, 26, 1165-1182.

37. L. F. Allard, S. H. Overbury, W. C. Bigelow, M. B. Katz, D. P. Nackashi and J. Damiano, Microsc Microanal, 2012, 18, 656-666.

38. L. F. Allard, W. C. Bigelow, M. Jose-Yacaman, D. P. Nackashi, J. Damiano and S. E. Mick, Microsc Res Techniq, 2009, 72, 208-215.

39. A. Chmielewski, C. Ricolleau, D. Alloyeau, G. Wang and J. Nelayah, Ultramicroscopy, 2020, 209, 112881.

40. C. A. Schneider, W. S. Rasband and K. W. Eliceiri, Nature Methods, 2012, 9, 671-675.

41. D. G. Lowe, Int J Comput Vision, 2004, 60, 91-110.

42. E. Donnelly and F. Mothe, Polar Transformer, https://imagej.nih.gov/ij/plugins/polartransformer.html, Accessed 01/22/2021.

43. J. Manaud, J. Maynadie, A. Mesbah, M. O. J. Y. Hunault, P. M. Martin, M. Zunino, N. Dacheux and N. Clavier, Inorg Chem, 2020, 59, 14954-14966.

44. V. Trillaud, J. Maynadie, J. Manaud, J. Hidalgo, D. Meyer, R. Podor, N. Dacheux and N. Clavier, Crystengcomm, 2018, 20, 7749-7760.

45. K. Popa, O. Walter, O. D. Blanco, A. Guiot, D. Bouexiere, J. Y. Colle, L. Martel, M. Naji and D. Manara, Crystengcomm, 2018, 20, 4614-4622.

46. G. I. Nkou Bouala, N. Clavier, R. Podor, J. Cambedouzou, A. Mesbah, H. P. Brau, J. Léchelle and N. Dacheux, Crystengcomm, 2014, 16, 6944-6954.

47. R. Podor, X. Le Goff, T. Cordara, M. Odorico, J. Favrichon, L. Claparede, S. Szenknect and N. Dacheux, Mater Charact, 2019, 150, 220-228.

48. X. G. Xue, R. L. Penn, E. R. Leite, F. Huang and Z. Lin, Crystengcomm, 2014, 16, 1419-1429.

49. Q. Zhang, S. J. Liu and S. H. Yu, J Mater Chem, 2009, 19, 191-207.

50. N. Wan, Z. Y. Shao, X. K. Zhao and K. Xu, Crystengcomm, 2019, 21, 4042-4047.

51. F. Cheng, L. Y. Lian, L. Y. Li, J. Y. Rao, C. Li, T. Y. Qi, Z. Zhang, J. B. Zhang and Y. H. Gao, Adv Sci, 2019, 6, 1802202.

52. R. Grupp, M. Nothe, B. Kieback and J. Banhart, Nat Commun, 2011, 2, 298.

53. R. Theissmann, M. Fendrich, R. Zinetullin, G. Guenther, G. Schierning and D. E. Wolf, Phys Rev $B, 2008,78,205413$.

54. P. Grammatikopoulos, C. Cassidy, V. Singh and M. Sowwan, Sci. Rep., 2014, 4, 5779.

55. T. M. Nenoff, B. W. Jacobs, D. B. Robinson, P. P. Provencio, J. Y. Huang, S. Ferreira and D. J. Hanson, Chem Mater, 2011, 23, 5185-5190.

56. V. Tyrpekl, M. Cologna, D. Robba and J. Somers, J Eur Ceram Soc, 2016, 36, 767-772.

57. E. Z. da Silva, G. M. Faccin, T. R. Machado, N. G. Macedo, M. de Assis, S. Maya-Johnson, J. C. Sczancoski, J. Andres, E. Longo and M. A. San-Miguel, J Phys Chem C, 2019, 123, 1131011318. 